\title{
ANALYSIS \\ Pastureland degradation and poverty among herders in Mongolia: Data analysis and game estimation
}

\author{
Wietze Lise ${ }^{\mathrm{a}, \mathrm{b}, *}$, Sebastiaan Hess ${ }^{\mathrm{b}}$, Byamba Purev ${ }^{\mathrm{c}}$ \\ a Energy Markets and International Climate Policy Group, ECN Policy Studies, Energy Research Centre of the Netherlands, \\ Badhuisweg 3, 1031 CM Amsterdam, The Netherlands \\ b Institute for Environmental Studies, Faculty of Earth and Life Sciences, Vrije Universiteit, De Boelelaan 1087, \\ 1081 HV Amsterdam, The Netherlands \\ ${ }^{\mathrm{c}}$ Centre for Policy Research CPR MONTSAME Building 206 Jigjidjav street 8 Ulaanbaatar 210620/A P.O. Box 29, Mongolia
}

Received 29 November 2004; accepted 11 July 2005

Available online 13 October 2005

\begin{abstract}
Since the beginning of the transition to a market economy herders in Mongolia are encountering enormous challenges. Degradation of pastureland as resulting from overgrazing pastures seriously jeopardizes the vulnerable livelihood of small herders' household economies. To analyse herder's grazing behavior, the Ugtaal district in the Tov province (north of the capital) and the Gurvansaikhan district in the Dundgovi province (south of the capital) have been selected.

In analysing collected primary data, it turns out with the help of a Principle Component Analysis that the herders in Ugtaal rank the perception of the quality of the environment second after a security factor, while the herders in Gurvansaikhan rank it first. A regression analysis indicates that richer herder do care more for the environment than poorer do in Ugtaal. Herders in Ugtaal face a reverse assurance game in choosing the growth in herd size. Hence, herd maximizing behavior leads to the highest payoff, while a second equilibrium exists where herders keep their herds constant. The herders in Gurvansaikhan also face a reverse assurance game in choosing the growth in herd size. The conclusion of this game is the same as for the game in Ugtaal. Hence, there are institutional alternatives in changing herder's behavior, but it comes at the cost of lowering their income from herding by about $30 \%$ in Gurvansaikhan, but the reduction can go up to $60 \%$ in Ugtaal.
\end{abstract}

(C) 2005 Elsevier B.V. All rights reserved.

Keywords: Pastureland degradation; Poverty among herders; Mongolia; Principal Component Analysis; Multiple regression; Estimation of game theoretic model

JEL classification: C31; C72; I32; Q29

\footnotetext{
* Corresponding author. Tel.: +31224 564511; fax: +31204922812.

E-mail address: lise@ecn.nl (W. Lise).
} 


\section{Introduction}

Since the beginning of the transition to a market economy herders in Mongolia are encountering enormous challenges. Degradation of pastureland as resulting from overgrazing pastures seriously jeopardizes the vulnerable livelihood of small herders' household economies.

After the collapse of communist rule in Mongolia, in 1991, the demise of the livestock collectives resulted in individual (household-based) livestock ownership, and unclear range management institutions. Between 1991 and 1998 the livestock enterprise rapidly expanded, partly assisted by relatively good weather conditions, and partly by many new entrants in the livestock economy, as a result of de-industrialisation of the urban economy. In 1990 Mongolia had 25.9 million domesticated animals. In 1998 this had grown to 32.9 million, an increase of $27 \%$. The increase was not a result of a growing number of sheep, in terms of domesticated animals the most numerous: the number of sheep even decreased slightly, from 15.1 million to 14.7 million. Also the number of camels had decreased: from 0.5 million to 0.4 million. The growth was due to increasing numbers of horses (from 2.3 million to 3.0 million), cattle and yaks (from 2.8 million to 3.7 million), and particularly goats (from 5.1 million to 11.1 million). The steep growth of the number of goats was a result of a strong demand for goat's hair, cashmere (NSOM, 2001).

Between 1990 and 1998 the weather conditions have been rather favorable. Compared to the 1980s rainfall was higher, and winters less severe (Batjargal et al., 2000). The carrying capacity of the Mongolian grazing lands improved, and the growing livestock population could, on average, be accommodated by these improved grazing conditions. However, changes in livestock mobility and range management styles, as well as unclear grazing institutions under privatised livestock management regimes, already created carrying capacity tensions in some areas. Where water wells were no longer maintained, some grazing areas were abandoned, resulting in condensed grazing in other areas. ${ }^{1}$

\footnotetext{
${ }^{1}$ According to CPR, 2003, out of 41,600 wells operational in 1990 , only 30,900 were still operational in 2000 .
}

Table 1

Livestock numbers in Mongolia, 1990, 1998 and 2002

\begin{tabular}{lrrrcl}
\hline & 1990 & 1998 & 2002 & $\begin{array}{l}\text { \% Change over } \\
\text { 1990-1998 }\end{array}$ & $\begin{array}{l}\text { \% Change over } \\
1998-2002\end{array}$ \\
\hline Horses & 2.3 & 3.0 & 1.1 & 33 & -64 \\
Cattle/yak & 2.9 & 3.7 & 1.9 & 30 & -49 \\
Camels & 0.5 & 0.4 & 0.3 & -26 & -35 \\
Sheep & 15.1 & 14.7 & 10.6 & -3 & -28 \\
Goats & 5.1 & 11.1 & 9.1 & 117 & -18 \\
Total & 55.3 & 69.9 & 39.0 & 26 & -44 \\
\hline
\end{tabular}

Total is expressed in sheep units (SU): 1 sheep $=1 \mathrm{SU}, 1$ horse $=7$ $\mathrm{SU}, 1$ cattle/yak $=6 \mathrm{SU}, 1 \mathrm{camel}=5 \mathrm{SU}, 1$ goat $=0.9 \mathrm{SU}$.

When, between 1999 and 2002, winter conditions deteriorated (with extreme $d z u d$ ), and spring-summer rainfall deteriorated as well, the results were quite disastrous for Mongolian livestock and for the expanded herder's community. It was estimated that 12 million animals died nationwide, and out of an estimated 190,000 herding households in 1998, 11,000 families lost all their animals (Danker, 2004, p. 26). In December 2002 the total number of animals had gone down to only 24 million, back to the level of the late 1980s. Compared to 1998 losses were most severe among horses $(-64 \%)$ and cattle $(-49 \%)$, and least severe among goats (only $-18 \%$ ). The numbers are presented in Table 1.

Government's policy shift for promoting more productivity-oriented strategies is likely to take long and intensive efforts until Mongolian herders adopt them. Traditionally, herders believe that after bad years good years come and they will be able to recover losses occurred during the bad years. This mentality persists to exist and appears to be a major psychological barrier preventing herders from preparing better for the-often-severe-winter season and it motivates herd maximizing behavior.

This paper aims at a demonstration of unsustainable herder's behavior through estimating the game among herders who compete for grazing pastures. A further objective of this paper is to identify the main dimensions of herder's behavior by undertaking a Principal Component Analysis. The hypotheses that guide the study are:

- The poorer the herders the worse the quality of their pastureland.

- The poorer the herders the greater the willingness to maximize the animal numbers. 
- It is optimal behavior for herders to maximize animal numbers.

- There are viable ways to change the herders' behavior towards social optimal animal numbers.

- Herder's behavior to maximize animal numbers creates long-term range degradation, which increases poverty.

To test these hypotheses we have gathered (empirical) information on three key sets of variables, namely (1) herder's income as a proxy for poverty, (2) change in animal numbers as a proxy for herder's behavior, and (3) herder's perception of the environment as a proxy for environmental degradation.

The outline of this paper is as follows. Section 2 starts with a presentation of the grazing situation in Mongolia, presenting specific details of two selected case study regions, Ugtaal and Gurvansaikhan, and discusses the data collected from herders in these case studies. The collected data is analysed in Section 3 by undertaking a Principle Component Analysis on the perception of herders with respect to their environment. Additionally, a multiple regression analysis is undertaken to verify, for instance, whether there is a link between poverty and herd size and/or perception of the environment. A game is set up and estimated in Section 4, in which herders compete on the use of pastureland. Section 5 draws conclusions.

\section{Description of the field setting}

\subsection{A specific look at two research areas: Ugtaal and Gurvansaikhan}

Two areas have been studied, namely one in the north, Ugtaal sum (with more rainfall-part of what is called the 'forest steppe'-and more severe winter conditions), and one in the south, Gurvansaikhan sum (with less rainfall, close to the Gobi desert, and less severe winter conditions).

These two districts have been selected using the following criteria:

- Different pasture degradation level, one with more degraded and another is less degraded
- Different ecological regions to represent a variety of ecological conditions and subsequent land use patterns

- Variation in terms of 1999-2001 dzud impacts

The selected sums are the Ugtaal sum of the Tov aimag and the Gurvansaikhan sum of the Dundgovi aimag, about which more specific details follow below.

\subsubsection{Ugtaal sum, Tov aimag}

The Ugtaal sum is located in Mongolia's steppe region and was created in 1924. The sum center is closer to the capital $(155 \mathrm{~km})$ than to its own aimag center $(177 \mathrm{~km})$. It covers a land area of 154.8 thousand ha out of which 110.7 thousand ha are pastures, 15.1 thousand ha are arable land and 1.2 thousand ha consist of haymaking areas. It also has 8.3 thousand ha of forest. According to the latest sum statistics 23.0 thousand ha of pastures were degraded.

The sum's population was 2816 as of January 2004, with total of 715 families. $74.8 \%$ of families (households with animals) own less than 200 animals. There are 270 families with up to 50 animals including non-herder's families (Table 2). From 2002 to 2003 the population and the number of livestock decreased by $9.3 \%$ and $7.0 \%$ respectively. The number of households with more than 200 animals was decreased by $24 \%$ while the number of households with up to 200 animals was decreased by $7.7 \%$.

The decreasing number of households is primarily explained by outward migration from Ugtaal to other sums. Local people explained that Ugtaal sum is not final destination for migrating households from the western provinces. Those migrating from the western provinces may stay few years in Ugtaal and migrate to the other places. For this reason 60 households and 340 people migrated in 2003 to the other places.

According to the general statistics the living standard of herding households in Ugtaal sum is decreasing (Table 2).

The main economic activity is livestock herding and crop farming. The sum animals have been severely affected by the $d z u d$ impacts in 2001-2002 In the year 2000 the number of livestock reached its maximum level of 152 thousand sheep units. At the end of 2003 there were only 86 thousand sheep units 
Table 2

The household's grouping by number of animals, Ugtaal sum

\begin{tabular}{|c|c|c|c|c|c|}
\hline \multirow[t]{2}{*}{ Indicators } & \multicolumn{5}{|l|}{ Years } \\
\hline & 1997 & 2000 & 2001 & 2002 & 2003 \\
\hline Population & 4170 & 3389 & 2974 & 3103 & 2816 \\
\hline Number of households & n.a. & 843 & 706 & 775 & 715 \\
\hline Of which households with animal herds including herders households & 794 & 656 & 557 & 562 & 508 \\
\hline \multicolumn{6}{|l|}{ Of which by percentage } \\
\hline Up to 10 heads & $13.9 \%$ & $10.1 \%$ & $11.8 \%$ & $14.1 \%$ & $15.6 \%$ \\
\hline $11-30$ heads & $26.2 \%$ & $16.5 \%$ & $16.7 \%$ & $15.8 \%$ & $22.6 \%$ \\
\hline $31-50$ heads & $15.5 \%$ & $14.8 \%$ & $17.4 \%$ & $17.3 \%$ & $15.0 \%$ \\
\hline $51-100$ heads & $23.0 \%$ & $25.6 \%$ & $23.3 \%$ & $24.0 \%$ & $23.0 \%$ \\
\hline $101-200$ heads & $15.2 \%$ & $16.9 \%$ & $18.1 \%$ & $17.3 \%$ & $14.2 \%$ \\
\hline 201-500 heads & $5.5 \%$ & $14.5 \%$ & $11.3 \%$ & $10.7 \%$ & $8.9 \%$ \\
\hline 501-999 heads & $0.4 \%$ & $1.5 \%$ & $1.1 \%$ & $0.7 \%$ & $0.6 \%$ \\
\hline 1000-1499 heads & $0.3 \%$ & $0.2 \%$ & $0.2 \%$ & $0.2 \%$ & $0.2 \%$ \\
\hline Above 1500 heads & $0 \%$ & $0 \%$ & $0 \%$ & $0 \%$ & $0 \%$ \\
\hline
\end{tabular}

Source: sum's livestock census data, 2003. n.a. means not available.

left in the sum (a decrease of 43\%). The available data on livestock numbers are presented in Table 3.

The Ugtaal sum has 4 areas of otor pastures, which covers 90.0 thousand ha. Those otor pastures are reserved for severe weather conditions.

2.1.1.1. The current situation of pasture use. The territory of Ugtaal sum geographically belongs to the forest steppe region south of the Khentii Mountains in the Mongolian steppe zone, following the Euro-Asian steppe region. Mountain steppes prevail in this area (Unatov, 1950).

Hummock grass and forbs are spread in the mountain meadow steppe (21.7 thousand ha or $20.3 \%$ ), and root-stem grass and hummock grass dominate in the mountain arid steppe (26.7 thousand ha or $27.7 \%$ ). Root-stem grass, hummock grass, couch, feather grass, bunchgrass, forbs dominate in the steppe

Table 3

Livestock number in Ugtaal sum

\begin{tabular}{lrrrrr}
\hline & 1999 & \multicolumn{1}{c}{2000} & \multicolumn{1}{c}{2001} & 2002 & \multicolumn{1}{c}{2003} \\
\hline Camel & 2 & 9 & 2 & 4 & 6 \\
Horse & 8402 & 7858 & 6949 & 6296 & 5490 \\
Cattle & 7088 & 6758 & 3836 & 3238 & 2630 \\
Sheep & 38,011 & 41,358 & 28,810 & 24,901 & 19,737 \\
Goat & 12,712 & 16,319 & 14,105 & 14,987 & 13,357 \\
Total & 150,804 & 151,644 & 113,174 & 101,909 & 85,998
\end{tabular}

Source: sum's livestock census data, 1999-2003.

Total is expressed in sheep units (SU): 1 sheep $=1 \mathrm{SU}, 1$ horse $=7$

$\mathrm{SU}, 1$ cattle $/ \mathrm{yak}=6 \mathrm{SU}, 1 \mathrm{camel}=5 \mathrm{SU}, 1$ goat $=0.9 \mathrm{SU}$.
(41.8 thousand ha or $39.0 \%$ ) and bunch grass, forbs are in the river steppe meadow (3.1 thousand ha or $2.9 \%)$.

Out of total pastureland 66.1 thousand ha $(62.0 \%)$ are pure, 23.0 thousand ha $(32.6 \%)$ are rocky, 7.9 thousand ha $(3.6 \%)$ are shrubby, 2.0 thousand ha $(1.2 \%)$ are hilly, while 2.9 thousand ha $(0.6 \%)$ are unsuitable for pasture.

Repeated overgrazing for longer periods all around the year adversely affects pasture vegetation growth and regeneration and leads to deterioration of the carrying capacity of pastureland. The Eastern region of Ugtaal sum is used for winter grazing, but these are now used continuously without any movement from one area to another.

Unsystematic grazing of animals leads to a change in vegetation composition, and useful species are replaced with less useful ones for feeding, such as chenopadium, artemisia and sedge. For example, pastures in the areas of Sevduul and Sovduul are more overgrazed.

Roads affected 1.2 thousand ha pastureland in the sum territory and it has been another factor for pasture degradation.

\subsubsection{Gurvansaikhan sum of the Dundgovi aimag}

The sum is located in the Gobi region. The district center lies $331 \mathrm{~km}$ south of the Ulaanbaatar and the distance to the aimag center is $71 \mathrm{~km}$. Its 542 thousand ha consist almost all (99\%) of pastureland. 
Table 4

The household's grouping by number of animal, Gurvansaikhan sum

\begin{tabular}{lrrrr}
\hline Statement & 2000 & 2001 & 2002 & 2003 \\
\hline Population & 2422 & 2462 & 2615 & 2690 \\
Total number of & 615 & 592 & 629 & 672 \\
$\quad$ households & 517 & 482 & 514 & 649 \\
Households with & & & & \\
$\quad$ animal herds including & & & & \\
herders' households & & & & \\
Of which by percentage & & & & \\
Up to 10 heads & $3.1 \%$ & $2.5 \%$ & $0.6 \%$ & $1.5 \%$ \\
$11-30$ heads & $11.4 \%$ & $4.8 \%$ & $5.8 \%$ & $8.3 \%$ \\
31-50 heads & $11.2 \%$ & $7.1 \%$ & $7.8 \%$ & $6.2 \%$ \\
$51-100$ heads & $28.0 \%$ & $21.1 \%$ & $18.1 \%$ & $20.0 \%$ \\
$101-200$ heads & $26.0 \%$ & $29.1 \%$ & $24.5 \%$ & $27.7 \%$ \\
201-500 heads & $16.1 \%$ & $27.2 \%$ & $34.2 \%$ & $27.0 \%$ \\
$501-999$ heads & $3.7 \%$ & $7.3 \%$ & $8.2 \%$ & $8.0 \%$ \\
$1000-1499$ heads & $0.5 \%$ & $0.8 \%$ & $0.6 \%$ & $1.2 \%$ \\
Above 1500 heads & $0.0 \%$ & $0.0 \%$ & $0.2 \%$ & $0.0 \%$ \\
\hline
\end{tabular}

Source: sum's livestock census 2000-2003.

The Gurvansaikhan sum's population was 2690 as of January 2003. Gurvansaikhan is one of the most sparsely populated sums in Mongolia, the population density is approximately 0.5 person per $\mathrm{km}^{2}$ and the density of families with livestock is 12 families per 100 $\mathrm{km}^{2}$ in 2003. According to the sum statistics, $36.2 \%$ of families own less than 200 animals. About $64 \%$ of households with herding animals have less than 200 heads in their herd and $16 \%$ has less than 50 animals. These numbers (see also Table 4) differ considerably from the numbers for Ugtaal (see also Table 2).

Similar to most other sums in Mongolia the primary economic activity is livestock herding. At the end of 2003 the sum had 203 thousand livestock (in sheep units). The overall number of livestock in Gurvansaikhan is increasing since 2000 (Table 5).

\subsubsection{Current pasture utilization. The territory of} Gurvansaikhan is characteristic of its geographic location, which lies across both the central Khalkh's steppe and the desert steppe region district Dornogovi. Vegetation cover is characterized by feather grass, feather grass-wild leek-anabasis and karaganafeather grass.

The sum's pasture yield per hectare is $210 \mathrm{~kg}$ in summer-autumn time, $170 \mathrm{~kg}$ in the winter-spring period. Fodder resources are 114 ktonnes in the summer-autumn, and 63.5 ktonnes in the winter-spring period. Annual average fodder resources reach 91.0 ktonnes. Herders permanently stay around winterspring camps which leads to pasture degradation and there is a lack of pasture preservation and effective regulation measures.

The traditional best practice of using pastures such as 4 seasonal rotations has been abandoned. Herders move only twice a year and the distance between seasonal camps has become lower than before. The animal pressure around the sum center, water sources, animal shelters and campsites tends to exceed the carrying capacity of the pastures.

Because of lack of regulation, the use of pastures becomes unorganized and unsystematic, which leads to overgrazing and degradation.

According to a pasture survey conducted in 1992, good pastureland accounted for $37.2 \%$ or 197 thousand ha of the total territory, and 16 thousand ha pasture was recorded as overgrazed. Another survey in 2002 demonstrated that overgrazed pastures had increased by $28.2 \%$. Overgrazed pastures are found in the area of Khongor Dukh Ovoo and the plain with lasiograstic splendens to the west of the sum center behind Ulaantolgoi and around the Ikh gazriin chuluu in the northern area of the sum.

\subsection{Data collected via a primary field survey}

The questionnaire for the survey was tested in Ugtaal and Gurvansaikhan in September and November 2003. The final survey was carried out in Ugtaal from 24 December to 8 January 2004, and in Gurvansaikhan between 14 and 26 January 2004.

The purpose of the survey was to select 30 families with a herd of less than 200 livestock and 30 families with more than 300 livestock from each survey site. In

Table 5

Livestock number in the Gurvansaikhan sum

\begin{tabular}{lrrrrr}
\hline & \multicolumn{1}{c}{1999} & \multicolumn{1}{c}{2000} & \multicolumn{1}{c}{2001} & \multicolumn{1}{c}{2002} & \multicolumn{1}{c}{2003} \\
\hline Camel & 1794 & 1465 & 1369 & 1324 & 1303 \\
Horse & 13,475 & 6701 & 7099 & 7628 & 8321 \\
Cattle & 10,157 & 1867 & 1673 & 2174 & 2862 \\
Sheep & 73,275 & 48,161 & 54,100 & 58,277 & 65,731 \\
Goat & 57,674 & 31,222 & 41,963 & 49,724 & 61,549 \\
Total & 289,419 & 141,695 & 158,443 & 176,089 & 203,059
\end{tabular}

Source: sum's livestock census 2000-2003.

Total is expressed in sheep units (SU): 1 sheep $=1 \mathrm{SU}, 1$ horse=7 $\mathrm{SU}, 1 \mathrm{cattle} / \mathrm{yak}=6 \mathrm{SU}, 1 \mathrm{camel}=5 \mathrm{SU}, 1$ goat $=0.9 \mathrm{SU}$. 
addition, local government officials and other local stakeholders were interviewed. Furthermore, secondary data has been gathered from the sum level livestock census, the so-called "A account". The data include very detailed information, which go back 7 years in Ugtaal (1997-2003) and 5 years in Gurvansaikhan (1999-2003).

The following general principles were used in undertaking the semi-structured interviews:

- The team members encouraged interviewees to express herders' opinions freely and made notes during the discussion. When required, interviewees were directed not to divert too far from the issue under consideration. In many cases the discussion went beyond the prior developed questionnaire to allow an interviewee to express important points;

- Traditions for women and young people not to dominate in discussions in the presence of elderly people may have to some degree influenced their participation in discussions although they have been encouraged to involve actively;

- In addition to the selection of herders with less than 200 and more than 300 livestock, it was also attempted to have a broad variation in terms of livestock numbers within the selected groups.

In total $85.3 \%$ of questions were answered and non-responses accounted for $14.7 \%$. Most herders were willing to express their environmental perception but they were more reserved towards answering questions related to income and expenditures.

\subsubsection{The survey in Ugtaal of Tov aimag}

In Ugtaal, the first meeting was held in the sum center with the vice governor of the sum, Mr. Tsagaankhuu, and followed by meetings with 3 bag governors. During the fieldwork the whole territory of the Ugtaal sum was covered by deep snow. Average snow depth was $30 \mathrm{~cm}$. For this reason the team discussed ways to reach herders with the bag governors. Three bag governors very much helped to implement the survey successfully. They first called the nearest herders into one of the herding households to allow the team to interview the herders. In total, the team visited 11 herding households to interview 60 herding household representatives. Respectively, 27,
24 and 9 households were interviewed in the Asgat, Taliin Uul and Khar Chuluut bags.

Compared to Gurvansaikhan, Ugtaal is much better located in relation to major markets. The primary advantage is its closeness to the capital city of Ulaanbaatar. Another advantage is that herders in Ugtaal have greater opportunity to prepare hay. The average amount of hay prepared by one household is 7 tonnes. At the time of survey, most herders had sent large flocks of animals to the otor pastures where snow depth was lower.

\subsubsection{The survey in Gurvansaikhan of Dundgovi aimag}

In time of organizing the final interview the weather condition of Gurvansaikhan was very favorable which helped the team to select herding households more freely and conduct the survey smoothly without any difficulties. In Gurvansaikhan sum the survey team used the same principle as in Ugtaal sum. Prior selection was made based on the number of animals. As indicated by the survey methodology, herding households were selected from 2 different groups of 30 households each, one with less than 200 animals and the other one with more than 300 animals. The survey team also discussed this household selection with the sum officials.

One of the bag governors, Mr. Tavaandelger, guided the survey team during the survey and provided many useful information. With his support, the survey team visited all 60 herding households for interviews. The survey included representatives from all 5 bags in Gurvansaikhan sum. Bag names are Suugaant bag, Dersen-Us bag, Elgen bag, Gurvansaikhan bag and Chuluut bag.

On an average, the sum herders migrate 5-8 times per year over distances of $4-11 \mathrm{~km}$. More than $80 \%$ of the herders have access to water within $5 \mathrm{~km}$ of their camps. Because of relatively good pastures, herders do not prepare much fodder. Still, a household prepares about 4-8 packs of hay, $20-50 \mathrm{~kg}$ of hand fodder and buys 1-2 sacks of bran.

Because of the subsistence nature of herder's households the domestic market for livestock products is very small in this sum. Major livestock products such as cashmere, meat and live animals are sold to traders from the aimag center and Ulaanbaatar City. Herders confirm that prices offered by 
local traders are usually lower than those offered by outside traders.

Poor herders in this sum face a difficult situation. They meet their demands for food and clothing mostly by helpful and wealthier relatives and friends in lowpaid and labour-intensive activities and they rely on rare welfare assistance from different sources. However, access to wealthy relatives and friends is not always reliable. Families who once helped their poor relatives tend to avoid doing so again if a chance occurs. Looking after animals owned by absentee herders appears to be an important source of livelihood for poor herders.

The PRA and secondary data from the livestock census were gathered to gain information about two variables: herder's behavior and herder's income.

Key variables to measure herder's behavior are:

- Livestock (sheep, goats, cattle, horses, camels) numbers over time.

- Specification of the male numbers of animals.

- Specification of the off-take and offspring of animals.

Key variables to measure herder's income are an overview of fodder purchases, veterinary services, sales of animals and animal products, as a proxy for the net income from the herd. Unfortunately own consumption by the household could not be included in the net income because the response to these questions in the survey was too incomplete.

Within Ugtaal and Gurvansaikhan districts, 60 families have been interviewed, which leads to a total number of 120 interviews, which can be used in the analysis. The interviews were matched with the yearly livestock census to gain a better insight into the livestock dynamics over time.

In order to estimate the game theoretic model as developed in Section 4, we derived the following variables from the data of herders at the household level:

(1) Herd growth rate, which is the difference between offspring and off-take divided by the total herd size to measure the herder's strategy. This data is widely and reliably available from the regular livestock census in Mongolia. We need to keep in mind that the total herd can also be influenced by hazards like droughts, dzud and diseases. This dependence can be avoided by focusing on a cross section within a single year. Here we focus on an analysis of the year 2003, for which sufficient data is available.

(2) With regard to the strategy of the herder, we also need a proxy for the net benefit of following that strategy. The net benefit consists of the income from sales of production minus the cost of production.

(3) To estimate a game, it is useful to obtain a proxy about the herder's belief of the combined strategy of all other competing herders. A good proxy for this is the perceptions of the environmental quality of the grazing pastures. Undertaking a Principle Component Analysis on a number of collected perceptive indicators can derive this proxy. The following questions have been used for this purpose:

- What is the current condition of the pastures?

- Have the pasture conditions changed compared to 10 years ago?

- Do you have access to otor pasture?

- Are you in favor of grazing reserves?

- Are the grazing reserves currently functioning well?

- Does your household have sufficient pasture to increase the herd size?

\section{Data analysis}

\subsection{Principle Component Analysis (PCA)}

In order to gain insight into the perception of herders with respect to their environment and the behavior of other herders, we have done a Principle Components Analysis (PCA) on a number of variables from our survey that we feel could reflect this perception. The PCA is used to reduce a number of variables to a few factors that best explain the variation in the variables. These factors can be seen as the underlying perception leading to the answers to our survey questions.

The selected variables are:

PCCUR: describes a herder's perception of the pasture conditions: if pasture conditions are con- 
Table 6

Principal component analysis of six environmental perception factors in the two studied districts in Mongolia

\begin{tabular}{|c|c|c|c|c|c|c|c|}
\hline & \multicolumn{2}{|c|}{ Combined factors } & \multicolumn{3}{|c|}{ Gurvansaikhan factors } & \multicolumn{2}{|c|}{ Ugtaal factors } \\
\hline & 1 & 2 & 1 & 2 & 3 & 1 & 2 \\
\hline Current pasture conditions & 0.029 & 0.862 & 0.777 & 0.162 & -0.216 & 0.180 & 0.893 \\
\hline Change in pasture conditions & -0.339 & 0.743 & 0.844 & -0.153 & 0.104 & -0.372 & 0.752 \\
\hline Access to otor pasture & 0.832 & -0.137 & -0.083 & 0.834 & 0.136 & 0.828 & -0.104 \\
\hline Attitude to grazing reserves & 0.626 & 0.101 & 0.048 & -0.035 & 0.919 & 0.747 & -0.148 \\
\hline Functioning of grazing reserves & 0.642 & -0.076 & 0.054 & 0.832 & -0.112 & 0.637 & -0.075 \\
\hline Sufficient pasture to increase the herd & 0.367 & 0.445 & 0.355 & -0.076 & -0.432 & 0.573 & 0.235 \\
\hline Variance explained & $30.6 \%$ & $24.0 \%$ & $26.1 \%$ & $24.0 \%$ & $16.9 \%$ & $36.9 \%$ & $23.1 \%$ \\
\hline Number of observations & 120 & & 60 & & & 60 & \\
\hline
\end{tabular}

sidered poor, this could indicate that the other herders have an aggressive strategy, i.e. they are maximizing their herd size. It is also a reflection of herders' behavior during the last few years. It is likely that the strategy of the previous years will be pursued in the future, as well.

PCCHANGE: describes a herder's perception of the change in pasture conditions during the last 10 years. A higher score on this variable indicates an improved condition. Just as PCCUR, this variable can reflect a herder's perception of other herder's behavior: a worsening of the pasture conditions can reflect a maximizing strategy.

ACCOTORP: describes the access to otor pasture. The rationale used for the previous variable is applicable here, as well: if otor pastures are not available this can indicate an aggressive strategy of the other herders.

ATTGR: describes a herder's attitude towards grazing reserves as a risk reduction tool. If herders feel grazing reserves are necessary, this can indicate that other herders' strategies are seen as threatening.

GRCUR: describes the current functioning of grazing reserves. A positive perception of this functioning can indicate that the behavior of other herders is not aggressive.

SUFPINC: describes a herder's assessment of the possibilities to increase his herd given the access to sufficient pastures.

This PCA is done for the combined survey of 120 questionnaires and for the two sums separately, covering 60 questionnaires each.

The Principle Components Analysis (PCA) results in three factors for the Gurvansaikhan case and two factors for both the combined survey and the Ugtaal case. This is presented in Table 6 .

The three dominating variables in the first factor of the combined survey Access to otor pasture, Attitude to grazing reserves, Functioning of grazing reserves are all related to risk management. A high score indicates that the herder perceives that he has several options in case of (unexpected) harsh weather conditions: he can either migrate to distant otor pastures or has access to well functioning grazing reserves (of which he holds a positive view) nearby. We can therefore describe this factor as an indicator of security. In Gurvansaikhan this factor is split into two. The actual risk management tools are dominant in the second factor, and the attitude towards one of these tools is dominating the third. In Ugtaal the same variables are again dominating the first factor together. Now, however, the variable Sufficient pasture to increase the herd is also dominant in the factor. This is also a component of security, matching with the explanation of the first factor of the combined data set.

The second factor in the combined survey is also found in both the Gurvansaikhan and the Ugtaal surveys separately. A high score on this factor indicates a positive perception of the pasture conditions: current pasture conditions are good and have improved compared to 10 years ago. A low score means the opposite: current conditions are poor and the pastures have deteriorated in the last 10 years. This factor seems to describe the perceived environmental conditions. We also see this as a good proxy for a herder's perception of the behavior of other herders, as it nicely captures the perceived collective outcome of the other herders. If there is much overgrazing, the pastures will be in a poor condition and 
Table 7

Meaning of the explanatory variables in the regression equations

\begin{tabular}{|c|c|}
\hline Variable & Explanation \\
\hline ISOLAT & $\begin{array}{l}\text { Sum of distances from summer and winter } \\
\text { camps to the bag and sum centers ( } 4 \text { distances) }\end{array}$ \\
\hline MOVE & Sum of distances between seasonal camps \\
\hline SEXS & Sex of the interviewed person \\
\hline AVAGE & Average age of the household \\
\hline NRWOM & Number of women in the household \\
\hline NRFM & Number of household members \\
\hline INCOME & $\begin{array}{l}\text { Total income in } 2003 \text { (sale of animals and } \\
\text { animal products and other income) }\end{array}$ \\
\hline
\end{tabular}

the other way around. In the combined survey, the variable Sufficient pasture to increase the herd is almost dominating, as well (and also positive, although of less importance, in both Gurvansaikhan and Ugtaal). This demonstrates how pasture conditions are perceived from the point of view of the herder and gives a proxy for their possibilities of extending their herd.

\subsection{Regression}

In order to gain insight into the possible explanations for the differences in perception, the following model is estimated for the factors derived in the previous section:

$$
\begin{aligned}
\text { Factor }_{i}= & \text { constant }+\beta_{1} \text { ISOLAT }+\beta_{2} \text { MOVE } \\
& +\beta_{3} \mathrm{SEXS}+\beta_{4} \mathrm{AVAGE}+\beta_{5} \mathrm{NRWOM} \\
& +\beta_{6} \mathrm{NRFM}+\beta_{7} \mathrm{INCOME}+\text { error }
\end{aligned}
$$

In addition, model (1) is also estimated for an indicator of herd growth and the fraction of male adult animals in the total herd, which are defined as (in sheep units, see Table 1):

Growth in herd size

$$
=(\text { offspring }- \text { off-take }) /(\text { total livestock })
$$

Fraction of male adults in herd

$$
=(\text { number of male adult animals }) /(\text { total livestock })
$$

Table 7 shows the meaning of the variables, which are included in the regression, while the results of the regressions are presented in Tables $8-10$. Statistical significant estimates are denoted by stars: $* P<0.10$; $* * P<0.05 ; * * * P<0.01$.

Table 8 shows that herder with a long movement and a higher number of female family members have a higher perception of security (first column). In addition, herders with a long movement and high incomes assign a higher perception to the environment. This indicates that income matters and it also indicates that relatively poorer herders tend to assign a lower value to their environment (second column). This result seems intuitive as richer herders are more powerful and can possibly easier secure good quality pastures, so that the poorer herders are cascading to pastures of lower quality. The result in the third column is insignificant, which indicates that there is no link between income and rate of herd growth, such that we cannot find evidence for our second hypotheses on the link between maximizing behavior and wealth. The result in the fourth column shows that a low frequency of movement explains the fraction of male adults in the herd, while the constant is also significant. All we can

Table 8

Regression result for the joined data set of both districts in Mongolia

\begin{tabular}{lcccr}
\hline & Perception of security & Perception of environment & Growth in herd size & Fraction of male adults in herd \\
\hline Constant & $-0.409(0.395)$ & $-0.133(0.411)$ & $0.122 * * *(0.039)$ & $0.253^{* * *}(0.051)$ \\
ISOLAT & $3.84 \mathrm{e}-03(0.003)$ & $1.97 \mathrm{e}-03(0.003)$ & $1.47 \mathrm{e}-04(0.00033)$ & $3.99 \mathrm{e}-04(0.00043)$ \\
MOVE & $5.89 \mathrm{e}-03 *(0.003)$ & $-6.00 \mathrm{e}-03 *(0.004)$ & $-2.00 \mathrm{e}-04(0.00034)$ & $-8.42 \mathrm{e}-04 *(0.00045)$ \\
SEXS & $-0.348(0.191)$ & $0.299(0.199)$ & $1.06 \mathrm{e}-02(0.019)$ & $1.19 \mathrm{e}-02(0.025)$ \\
AVAGE & $-1.13 \mathrm{e}-02(0.007)$ & $-4.59 \mathrm{e}-03(0.008)$ & $6.03 \mathrm{e}-04(0.001)$ & $-2.96 \mathrm{e}-04(0.001)$ \\
NRWOM & $0.24 * *(0.111)$ & $-6.15 \mathrm{e}-02(0.115)$ & $6.15 \mathrm{e}-03(0.011)$ & $-5.02 \mathrm{e}-03(0.014)$ \\
NRFM & $-5.73 \mathrm{e}-02(0.075)$ & $5.16 \mathrm{e}-02(0.078)$ & $4.00 \mathrm{e}-03(0.007)$ & $8.72 \mathrm{e}-04(0.01)$ \\
INCOME & $1.26 \mathrm{e}-07(9.5 \mathrm{e}-08)$ & $1.97 \mathrm{e}-07 * *(9.8 \mathrm{e}-08)$ & $2.05 \mathrm{e}-09(9.4 \mathrm{e}-09)$ & $-1.20 \mathrm{e}-08(1.2 \mathrm{e}-08)$ \\
$R^{2}$ adjusted & 0.12 & 0.048 & -0.034 & -0.015 \\
\hline
\end{tabular}


Table 9

Regression result for the district Gurvansaikhan

\begin{tabular}{lcccrr}
\hline & $\begin{array}{l}\text { Perception of } \\
\text { environment }\end{array}$ & $\begin{array}{l}\text { Perception of } \\
\text { security } 1\end{array}$ & $\begin{array}{l}\text { Perception of } \\
\text { security } 2\end{array}$ & Growth in herd size & $\begin{array}{l}\text { Fraction of male } \\
\text { adults in herd }\end{array}$ \\
\hline (Constant) & $0.283(0.58)$ & $-0.184(0.497)$ & $-0.399(0.569)$ & $0.171 * * *(0.052)$ & $0.259 * * *(0.057)$ \\
ISOLAT & $-7.77 \mathrm{e}-03(0.005)$ & $3.52 \mathrm{e}-03(0.004)$ & $4.74 \mathrm{e}-03(0.005)$ & $9.16 \mathrm{e}-05(0.0001)$ & $-1.54 \mathrm{e}-04(0.0001)$ \\
MOVE & $4.64 \mathrm{e}-03(0.011)$ & $7.74 \mathrm{e}-03(0.009)$ & $3.00 \mathrm{e}-03(0.01)$ & $-1.87 \mathrm{e}-03 *(0.001)$ & $6.70 \mathrm{e}-04(0.001)$ \\
SEXS & $0.145(0.287)$ & $-0.561 *(0.246)$ & $-0.161(0.282)$ & $-1.61 \mathrm{e}-02(0.026)$ & $6.89 \mathrm{e}-02 * *(0.028)$ \\
AVAGE & $-1.07 \mathrm{e}-02(0.011)$ & $-1.08 \mathrm{e}-02(0.009)$ & $-1.13 \mathrm{e}-02(0.01)$ & $8.25 \mathrm{e}-04(0.001)$ & $2.18 \mathrm{e}-04(0.001)$ \\
NRWOM & $0.106(0.18)$ & $0.531^{* * *}(0.155)$ & $0.334^{*}(0.177)$ & $1.17 \mathrm{e}-02(0.016)$ & $-2.09 \mathrm{e}-02(0.018)$ \\
NRFM & $5.31 \mathrm{e}-02(0.109)$ & $-0.288^{* * *}(0.094)$ & $-4.16 \mathrm{e}-02(0.107)$ & $-3.17 \mathrm{e}-03(0.01)$ & $6.39 \mathrm{e}-03(0.011)$ \\
INCOME & $-2.94 \mathrm{e}-08(1.3 \mathrm{e}-07)$ & $3.33 \mathrm{e}-07 * * *(1.1 \mathrm{e}-07)$ & $-9.06 \mathrm{e}-08(1.3 \mathrm{e}-07)$ & $6.18 \mathrm{e}-09(1.2 \mathrm{e}-08)$ & $-1.98 \mathrm{e}-08(1.3 \mathrm{e}-08)$ \\
$R^{2}$ adjusted & -0.004 & 0.261 & 0.034 & -0.02 & 0.076 \\
\hline
\end{tabular}

conclude from this is that herds with relatively many male adults tend to move over shorter distances.

Table 9 has five columns, as there are three factors for the case of Gurvansaikhan. The first column is fully insignificant. This means that for the case of Gurvansaikhan we do not find any explanation for the variance in perception of environmental variability, which also indicates that we have no evidence for accepting the first hypothesis on the link between environment and wealth. The second column shows the most significant result of all the regressions. Male respondents, small families with relatively many women who are relatively rich, explain a positive attitude to otor pastures and grazing reserves. The second indicator of security follows the same pattern and confirms the previous result for the number of women in the family (third column). The fourth column shows that herders with lower intensity of movement tend to increase their herd size. The result of the fifth column indicates that female-headed families tend to rear herd with relatively more male adults. We cannot give any intuition for finding such kind of a result.
Table 10 shows the result for Ugtaal. The first and third columns of the four regressions are totally insignificant. This means that we do not find any explanation for the perception of security and the maximizing behavior of herders in Ugtaal, while the fourth column is only explained by a trivial significant constant, which also does not help much. The second column, however, presents us with an important correlation, namely that herders with a higher level of income tend to have a better perception of the pasture conditions. We already found this result in the regression for the pooled data set. Once again we have some evidence for the hypothesis that poorer herders face a worse environment in the district of Ugtaal.

\section{Game estimation}

\subsection{The inter-herder game in Mongolia}

Consider the following situation. It is November and winter is about to start. Imagine a delineated winter grazing area in a Mongolian region. The sum-

Table 10

Regression result for the district Ugtaal

\begin{tabular}{lccrr}
\hline & Perception of security & Perception of environment & Growth in herd size & Fraction of male adults in herd \\
\hline Constant) & $4.23 \mathrm{e}-02(0.658)$ & $-1.359 * *(0.668)$ & $8.66 \mathrm{e}-02(0.067)$ & $0.2 * *(0.095)$ \\
ISOLAT & $1.49 \mathrm{e}-03(0.006)$ & $5.29 \mathrm{e}-03(0.006)$ & $4.48 \mathrm{e}-04(0.001)$ & $1.11 \mathrm{e}-03(0.001)$ \\
MOVE & $7.80 \mathrm{e}-03(0.006)$ & $-1.51 \mathrm{e}-03(0.006)$ & $-3.81 \mathrm{e}-04(0.001)$ & $-1.08 \mathrm{e}-03(0.001)$ \\
SEXS & $-0.481(0.29)$ & $0.341(0.294)$ & $3.82 \mathrm{e}-02(0.029)$ & $-4.86 \mathrm{e}-02(0.042)$ \\
AVAGE & $-1.72 \mathrm{e}-02(0.012)$ & $1.56 \mathrm{e}-02(0.012)$ & $3.46 \mathrm{e}-05(0.001)$ & $-9.20 \mathrm{e}-04(0.002)$ \\
NRWOM & $0.195(0.166)$ & $-8.78 \mathrm{e}-02(0.169)$ & $-1.93 \mathrm{e}-03(0.017)$ & $-6.08 \mathrm{e}-03(0.024)$ \\
NRFM & $-7.35 \mathrm{e}-02(0.125)$ & $0.107(0.127)$ & $1.76 \mathrm{e}-02(0.013)$ & $7.09 \mathrm{e}-03(0.018)$ \\
INCOME & $-2.95 \mathrm{e}-08(2 \mathrm{e}-07)$ & $4.43 \mathrm{e}-07 * *(2 \mathrm{e}-07)$ & $2.40 \mathrm{e}-09(2 \mathrm{e}-08)$ & $1.36 \mathrm{e}-08(2.9 \mathrm{e}-08)$ \\
$R^{2}$ adjusted & 0.09 & 0.063 & -0.043 & -0.066 \\
\hline
\end{tabular}


mer grass-growth season is over and the winter pasture is restored and ready to be grazed. This is the time for the herders to decide on the off-take in their herds by slaughtering a number of their animals.

This situation can be formalised by identifying strategies and players in a game as follows. The herders are playing a game about the herd size to maintain. There are, however, consequences for the decisions of herders, as when they choose to maximize their herd sizes, the risk of negative impacts of possible future $d z u d$, droughts and diseases increases. On the other hand when they have high off-takes from their herd size, they may not fully benefit from the (winter) grazing opportunity. Taking these considerations into account, we can demonstrate the mechanism of this game by a metaphorical two-person two-strategy representation.

In order to formalise possible conflicts, which can emerge between herders, let us restrict the analysis to two equal herders $\{1,2\}$. In the case with $n$ herders contesting for grazing pastures, we can distinguish between Herder 1, the challenger, and Herder 2, the contender, which is composed of all other herders contesting for the same winter pasture. For that we need to assume that the challenger interprets the actions of other herders as a simultaneous move. Hence, we are dealing with a 1 versus $n-1$ persons game (see also Lise, 2001; Lise et al., 2001). ${ }^{2}$

The herders choose their herd size, which induces the survival rate of their herd and, hence, their payoff. When both herders keep their livestock constant they obtain $x$, when the herders increase their livestock they obtain $y$, when one herder increases his/her herd and the other keeps his/her herd constant, the herd increasing herder obtains $a$ and the herd maintaining herder obtains $b$. Note that since we start our analysis from the view-point of a normal year, the herders know that they can have access to well-stocked pastures, even if it would not be sustainable in the longer term. Table 11 shows the resulting payoff matrix.

If the contender maintains his/her herd, there will be more grass left for the challenger who can feed his/ her herd without purchasing additional and expensive fodder. If the contender maximizes his/her herd size, it

\footnotetext{
${ }^{2}$ One of the earliest accounts of games among herders is the herdsman game as formulated by Musham (1973), which is also put in a 1 versus $n-1$ person setting.
}

Table 11

Payoff matrix for the game between two symmetric herders

\begin{tabular}{llll}
\hline & \multicolumn{2}{l}{ Herder 2 (contender) } \\
\cline { 3 - 4 } & $\begin{array}{l}\text { Keep herd } \\
\text { constant }\end{array}$ & $\begin{array}{l}\text { Increase } \\
\text { herd size }\end{array}$ \\
\hline Herder 1 & Keep herd constant & $x, x$ & $b, a$ \\
(challenger) & Increase herd size & $a, b$ & $y, y$ \\
\hline
\end{tabular}

is still better for the challenger to do the same, as (s)he is not sure when (s)he accesses the winter pasture in future, that the pasture will be in good grazing condition. This depends on weather conditions and possible overgrazing by other herders. Both herders, however, are better off with a mutual constant herd size, so that they are in a better position to face a possible $d z u d$, since the impact of a $d z u d$ will be much more severe in the case of a large herd size in the beginning of an extreme cold period. The same reasoning is true for droughts, where it is much more difficult to maintain a large herd size during a drought than a smaller more mobile herd size. Following this argument, we hypothesise that game of setting the herd size resembles a prisoner's dilemma:

$a>x>y>b$

Such a situation, where mutual cooperation is only possible through communication and trust (see for instance Fukuyama, 1995), is difficult to resolve. Another possibility to achieve mutual cooperation is through utility transfer on which Bromley (1998) provides the economic rationale for an irrigation system where head enders put an externality on tail enders. Institution building is also an option, as well-pointed out grazing rights can avoid conflicts over grazing pastures and provide an insurance to farmers that a present conservative behavior can be rewarded with a future access to greener pastures. Communication, trust, transfers and well-defined property rights are all institutional correcting measures to change prisoner's dilemmas into harmonious situations. ${ }^{3}$

Hence, we hypothesise that herders will maximize their herd sizes, because there are no well-defined grazing rights, which can protect their current lower

\footnotetext{
${ }^{3}$ See for instance Ostrom (1990) and Ostrom et al. (1994) for the linkage between institutions and resource management.
} 
level of grazing, while being fully aware that this increases their vulnerability to $d z u d$ risk.

\subsection{Technical description of the game estimation procedure}

For estimating the herder's game we need to construct the triple $\left(\pi_{i}, \theta_{i}, \vartheta_{i}\right)$, where $\pi_{i}$ is the payoff for household $i$, measured as the net income from the herd, while $\theta_{i}$ is the strategy for household $i$, measured as the growth rate of the herd. The by the challenger perceived strategy of all other herders, the contenders $\vartheta_{i}$, can be derived by taking the perceived environmental condition, which is the second factor in Ugtaal and the first factor in Gurvansaikhan.

To interpret the value of the strategy, it is useful to normalize the strategy of the challenger $\theta_{i}$ and the strategy of the contender $\vartheta_{i}$. In general, variable $s_{i}$ can be converted into a fraction between 0 and 1 as follows:

$$
\tilde{x}_{i}=\frac{s_{i}-\min _{k \in N} s_{k}}{\max _{k \in N} s_{k}-\min _{k \in N} s_{k}} \text { for all } i \in N
$$

The households can be assigned to four clusters, so that the Euclidean distance within clusters is minimized, while the Euclidean distance between clusters is maximized. ${ }^{4}$ The Euclidean Cluster Method (ECM) yields final cluster centers. The following table shows how to assign the final cluster centers of the actions of the challenger $(\theta)$ and the contender $(\vartheta)$ to payoff-groups $A, B, X, Y$.

Alternatively it is also possible to assign the payoffs into four payoff groups by taking 0.5 as the threshold value. Let us then define values of $\theta$ and $\vartheta$ above 0.5 as participative behavior in the sense that herders try to keep their herd size constant, while values of $\theta$ and $\vartheta$ below 0.5 indicates that herders are trying the expand their herd size. Let us refer to this simple way of splitting the payoffs as the Simple Threshold Method (STM). Assigning the payoffs is done as before and as shown in Table 12.

\footnotetext{
${ }^{4}$ This is possible through a standard procedure of SPSS (Norusis, 1990).
}

Table 12

Assigning households into clusters, using final cluster centers

$\begin{array}{lll}\text { Choice of the herder }(\theta) & \text { Choice of other herders }(\vartheta) & \text { Payoff }\end{array}$ group

'Increase herd size'

'Increase herd size'

'Keep herd size constant'

'Keep herd size constant'

\begin{tabular}{ll} 
'Increase herd size' & $Y$ \\
'Keep herd size constant' & $A$ \\
'Increase herd size' & $B$ \\
'Keep herd size constant' & $X$ \\
\hline
\end{tabular}

Finally, the payoffs can be calculated by applying formula (6), where $|X|$ denotes the number of observations in payoff-group $X$ :

$$
\begin{aligned}
a & =\frac{1}{|A|} \sum_{i \in A} \pi_{i} ; b=\frac{1}{|B|} \sum_{i \in B} \pi_{i} ; x \\
& =\frac{1}{|X|} \sum_{i \in X} \pi_{i} ; y=\frac{1}{|Y|} \sum_{i \in Y} \pi_{i}
\end{aligned}
$$

\subsection{Results}

The estimation procedure as explained in the previous section is applied to derive the games in Ugtaal and Gurvansaikhan. In order to obtain insight in the assignment of payoffs to payoff groups, the choices of the challenger and the contender are plotted in Figs. 1 and 2 . The choice of the challenger, $\theta$, represents the growth in herd size; a high $\theta$ represents low growth, while a low $\theta$ represents high growth. The choice of the contender, $\vartheta$, represents the perception of the environment; a high $\vartheta$ is a positive perception, while a low $\vartheta$ means a negative perception. Figs. 1 and 2 show both the result in the case of the ECM and the STM. Division based on the ECM is represented by diamonds, triangles, circles and squares, while a division based on the STM is shown by the thick lines in Figs. 1 and 2.

Interpretation of Figs. 1 and 2 already leads to an interesting outcome, namely that there is more herd size maximizing behavior in Ugtaal than in Gurvansaikhan. This is shown in the figures by the concentration of data at the down-left side in Ugtaal (increasing herd size, quality of the environment perceived to be low) and the right side in Gurvansaikhan (more constant herd size, irrespective of perceived environmental quality).

The game estimation results, using the primary data as explained in Section 2, are presented in Table 13. 


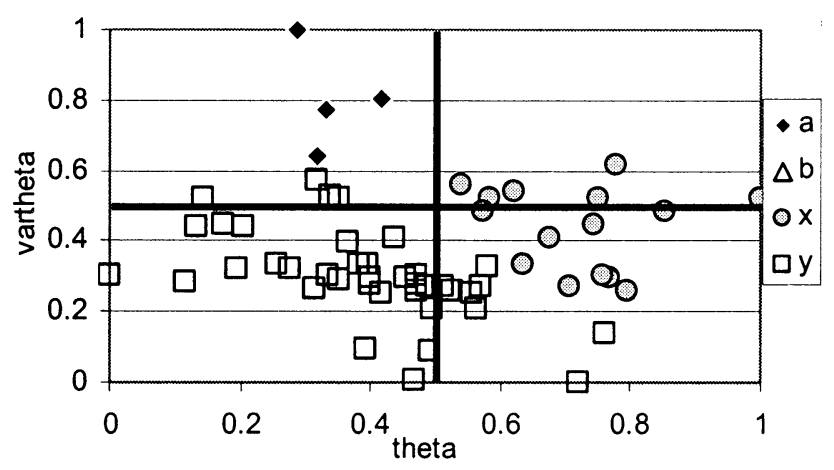

Fig. 1. Scatterplot of strategies in Ugtaal.

In interpreting the results as presented in Table 13, the game in Ugtaal is ambiguous. On the one hand, we find a prisoner's dilemma as hypothesised in Eq. (4) with the ECM. If this were the case, then it is presently equilibrium behavior to maximize the herd size, however, there is an institutional viable alternative where the herders are better off. Inspection of Fig. 1 yields that the division of payoffs based on the ECM is a bit arbitrary. On the other hand, the STM yields a reverse assurance game. If this is the right representation of the current situation, then there are two equilibria in Ugtaal, however, the maximizing herd size equilibrium leads to the highest payoff. Fig. 1 shows that there is quite some difference between the division of strategies using ECM and STM. The STM division seems to get closer to reality.

The game in Gurvansaikhan is easier to interpret. We find with both division methods the same reverse assurance game. The interpretation of this game is the same as for the second game in Ugtaal, namely that there are two equilibria, however, the maximizing herd size equilibrium leads to the highest payoff.

Hence, there are viable institutional alternatives for herders to change their behavior from herd maximization (most common in Ugtaal) to keeping the herd size constant. However, this institution needs to compensate them for the loss of income due to keeping a small herd. If such a mechanism can be put in place a transition to sustainable pasture management will become within reach.

This result also links up well with the carrying capacity dynamics as undertaken in Dietz et al. (2004). According to their analysis the dynamic (dependent on variation of temperature and precipitation) carrying capacity of the more densely populated and relatively green district of Ugtaal is not yet crossed, except during the dzud in 1998. They also claim that the dynamic carrying capacity is exceeded in the dryer and sparsely populated district of Gurvansaikhan. That the game in Gurvansaikhan still does not show a lower payoff for maximizing the herd size may

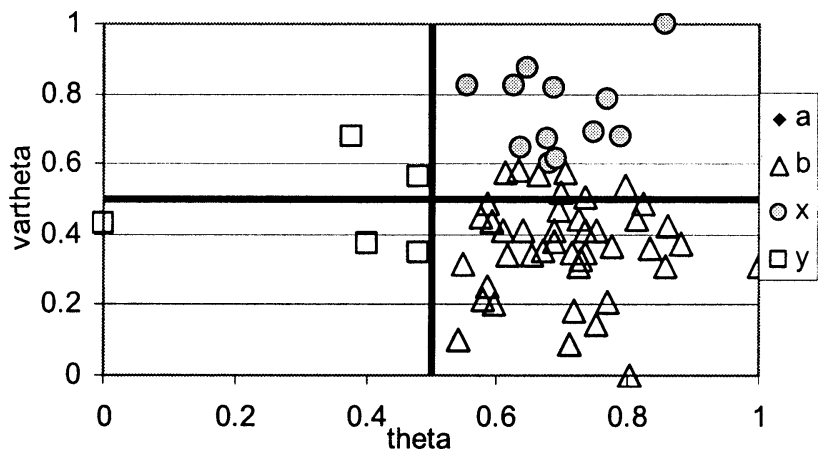

Fig. 2. Scatterplot of strategies in Gurvansaikhan. 
Table 13

The estimated herder game using primary data, strategy is to choose herd growth rate

\begin{tabular}{lllllll}
\hline & $a$ & $b$ & $x$ & $y$ & Payoff order & Name of the game \\
\hline Ugtaal.ECM & $1246.6(4)$ & & $487.4(15)$ & $241.6(41)$ & $a>x>y>b$ & Prisoner's dilemma \\
Ugtaal.STM & $248.1(27)$ & $455.3(19)$ & $268.9(6)$ & $655.0(8)$ & $y>b>x>a$ & Reverse assurance game \\
Gurvansaikhan.ECM & & $1017.3(43)$ & $967.1(12)$ & $1049.2(5)$ & $y>b>x>a$ & Reverse assurance game \\
Gurvansaikhan.STM & $862.0(3)$ & $1126.9(19)$ & $942.8(36)$ & $1330.1(2)$ & $y>b>x>a$ & Reverse assurance game \\
\hline
\end{tabular}

The number in the brackets denotes the number of observations within the payoff group. Payoffs are expressed in thousands of the local Mongolian currency Tugrik, which was equivalent to $0.74 €$ at the time of the survey.

indicate that the worsening environment has not yet led to repercussions on the income of herders. Also the absolute number of herders with fast growing herds is very small (i.e. Fig. 2) in Gurvansaikhan. To find a higher payoff under herd maximization in Ugtaal supports the claim that there is still space for increasing the herd there. Hence, the game based on the STM seems to be the most representative for the situation in Ugtaal, rejecting the hypothesis that the herder's herd increasing game is a prisoner's dilemma. Rather it is a reverse coordination game in Ugtaal and a reverse assurance game in Gurvansaikhan.

\section{Conclusions}

The hypotheses that guided the study were:

- The poorer the herders the worse the quality of their pastureland.

- The poorer the herders the greater the willingness to maximize the animal numbers.

- It is optimal behavior for herder's to maximize animal numbers.

- There are viable ways to change the herders' behavior towards social optimal animal numbers.

- Herder's behavior to maximize animal numbers creates long-term range degradation, which increases poverty.

A Principle Component Analysis on the perception of herders with respect to their environment gave a mixed result. On the one hand, herders in Gurvansaikhan give the highest importance to the environment and have a mixed attitude to grazing security as the second and third factor. On the other hand, herders in Ugtaal value grazing security as most important, while their perception of the environment is their second factor.
Regressions with the primary data accept the first hypothesis that poorer herders have a worse perception of the quality of the environment in the case of Ugtaal and the joined cases, while we do not find such a result in Gurvansaikhan. We do not find any evidence for the second hypothesis. On average, the herders in Ugtaal are poorer than the herders in Gurvansaikhan. Still this difference is not statistically significant in the regressions.

The estimated games indicate indeed that it is optimal behavior to maximize herds. We find viable way of changing behavior both in Ugtaal and Gurvansaikhan. However, this behavioral change is difficult to achieve, as it involves a move from an equilibrium with a high payoff to an equilibrium with a lower payoff. This decrease can grow to $30 \%$ in Gurvansaikhan and up to $60 \%$ in Ugtaal. Hence, a policy recommendation is that alternative herder behavior can be achieved, but there are considerable costs involved to make it attractive for the herders to make this switch.

\section{Acknowledgements}

A previous draft of this paper was accepted for presentation at the Eight Meeting of the International Society for Ecological Economics; Montreal, Ont. Canada; July 11-14, 2004. We are thankful for the valuable discussions with our project partners Ton Dietz, Enkh-Amgalan and Tumur Erdenechuluun. We are grateful to DGIS/PREM for funding this project.

\section{References}

Batjargal, Z., Dagvadorj, D., Batima, P. (Eds.), 2000. Mongolia National Action Programme on Climate Change. Ulaanbaatar: 
National Agency for Meteorology, Hydrology and Environment Monitoring and JEMR Publishing.

Bromley, D.W., 1998. Property regimes and pricing regimes in water resource management. Paper Presented at the World Bank Sponsored Workshop on Political Economy of Water Pricing Implementation, Washington D.C., November 3-5.

Danker, M., 2004. Hörs-Gazar. Cry of a woken bull. Changes in pastoral life and pastureland management in Mongolia. Amsterdam: Vrije Universiteit (MSc Thesis, as part of PREM programme).

Dietz, T., Hess, S., Enkh-Amgalan, Chuka, 2004. Carrying capacity dynamics and prospects for livestock commercialisation as a way out of land degradation in Mongolia's free market era, working document of the PREM programme

Fukuyama, F., 1995. Trust: Social Virtues and the Creation Of. The Free Press, New York.

Lise, W., 2001. Estimating a game theoretic model. Computational Economics 18 (2), 141-157.

Lise, W., Garrido, A., Iglesias, E., 2001. A game model of farmer's demand for irrigation water from reservoirs in Southern Spain. Risk Decision and Policy 6 (3), 167-185.
Muhsam, H.V., 1973. A world population policy for the world population year. Journal of Peace Research 10 (1/2), 91-99.

Norusis, M.J., 1990. SPSS/PC+ Statistics 4.0 for the IBM PC/XT/ AT and PS/2. SPSS Inc., Chicago.

NSOM, 2001. National Statistical Office of Mongolia, and World Bank, Mongolia, Participatory Living Standard Assessment 2000, Summary report prepared for the Donor Consultative Group Meeting, Paris, May 15-16, 2001.

Ostrom, E., 1990. Governing the Commons, The Evolution of Institutions for Collective Action. Cambridge University Press, Cambridge.

Ostrom, E., Gardner, R., Walker, J., 1994. Rules, Games and Common-pool Resources. Ann Arbor, The University of Michigan Press, Michigan.

Unatov, A.A., 1950, "Mongolian useful plants", unpublished, stored at State library and steel, considered as valuable material for researchers working on useful and medicinal plants. 